\title{
Erratum to: Epigenetic regulation of DNA methyltransferases: DNMT1 and DNMT3B in gliomas
}

Ganeshkumar Rajendran • Karthik Shanmuganandam • Ameya Bendre · Dattatraya Muzumdar •

Abhay Goel $\cdot$ Anjali Shiras

Published online: 10 February 2011

(C) Springer Science+Business Media, LLC. 2011

Erratum to: J Neurooncol

DOI 10.1007/s11060-010-0520-2

The fourth author's name was misspelt in the original publication. It is correct in this erratum.

The online version of the original article can be found under doi:10.1007/s11060-010-0520-2.

G. Rajendran $\cdot$ K. Shanmuganandam ·

A. Bendre · A. Shiras $(\square)$

National Centre for Cell Science (NCCS), Pune, India

e-mail: anjalishiras@nccs.res.in

D. Muzumdar · A. Goel

Seth GS Medical College and KEM Hospital, Mumbai, India 